Rochester Institute of Technology

RIT Scholar Works

Presentations and other scholarship

Faculty \& Staff Scholarship

8-2019

\title{
Publication and Evaluation Challenges in Games \& Interactive Media
}

Elizabeth L. Lawley

Rochester Institute of Technology

Follow this and additional works at: https://scholarworks.rit.edu/other

Part of the Digital Humanities Commons, Game Design Commons, Other Computer Sciences

Commons, Scholarly Communication Commons, and the Scholarly Publishing Commons

\section{Recommended Citation}

Elizabeth Lane Lawley. 2019. Publication and Evaluation Challenges in Games \& Interactive Media. In Proceedings of the 13th International Conference on the Foundations of Digital Games (FDG '19). San Luis Obispo, CA, USA

This Conference Paper is brought to you for free and open access by the Faculty \& Staff Scholarship at RIT Scholar Works. It has been accepted for inclusion in Presentations and other scholarship by an authorized administrator of RIT Scholar Works. For more information, please contact ritscholarworks@rit.edu. 


\title{
Publication and Evaluation Challenges in Games \& Interactive Media
}

\author{
Elizabeth Lane Lawley \\ School of Interactive Games \& Media \\ Rochester Institute of Technology \\ Rochester, NY \\ Elizabeth.Lawley@rit.edu
}

\begin{abstract}
Faculty in the fields of games and interactive media face significant challenges in publishing and documenting their scholarly work for evaluation in the tenure and promotion process. These challenges include selecting appropriate publication venues and assigning authorship for works spanning multiple disciplines; archiving and accurately citing collaborative digital projects; and redefining "peer review," impact, and dissemination in the context of creative digital works. In this paper I describe many of these challenges, and suggest several potential solutions.
\end{abstract}

\section{CCS CONCEPTS}

- Digital libraries and archives - Combination, fusion and federated search

\section{KEYWORDS}

Games, interactive media, scholarly communication, interdisciplinary research, academic disciplines, peer evaluation, promotion and tenure, institutional repositories

\section{ACM Reference format:}

Elizabeth Lane Lawley. 2019. Publication and Evaluation Challenges in Games \& Interactive Media. In Proceedings of the 13th International Conference on the Foundations of Digital Games (FDG '19). San Luis Obispo, CA, USA

\section{Games \& Interactive Media in the Academy}

Games and interactive media as a discipline is quite young in the context of academia-fewer than 30 years have passed since Abertay University's School of Design \& Informatics established the first undergraduate computer gaming degree in 1997 [1].

Permission to make digital or hard copies of part or all of this work for personal or classroom use is granted without fee provided that copies are not made or distributed for profit or commercial advantage and that copies bear this notice and the full citation on the first page. Copyrights for third-party components of this work must be honored. For all other uses, contact the owner/author(s).

FDG'19, August, 2019, San Luis Obispo, CA, USA

(C) 2019 Copyright held by the owner/author(s).
Since then, the number of programs has grown significantly; in April of 2019, the Entertainment Software Association's database of college video game programs listed over 400 colleges offering bachelor's degrees in the United States alone [15]. However, those programs-and the faculty within them-represent a disparate range of disciplinary roots and affiliations.

A common characteristic of games and interactive media programs is that they integrate technology, art, and media into both their curriculum and their faculty expertise. While many (though certainly not all) degree programs in games and interactive media are now housed in their own departments, those departments in turn are typically housed within a school or college with a narrower disciplinary focus. A review of just the top ten graduate game design programs listed in the 2019 Princeton Review rankings shows a wide range of parent colleges, including Fine Arts, Cinematic Arts, Digital Media Arts, Media Arts \& Design, Arts \& Humanities, Design \& Informatics, Communication Arts and Sciences, Computing and Information Sciences, Engineering, and Arts \& Humanities [47].

While the academic home for a games and interactive media program has a clear impact on its overall direction-one is unlikely to find a humanities-focused game studies program in an engineering college, for instance, or a programming-focused game development program in a communication college-many programs include faculty representing a more diverse range of disciplines than is generally found within their parent colleges.

\section{Challenges in the Evaluation Process}

Interdisciplinary research frequently presents significant challenges and barriers related to promotion and tenure, and research into games and interactive media is no exception. Scholars whose work encompasses creative digital works-such as original games, or interactive performances-face additional difficulties in the dissemination, description, and impact assessment their work. 


\subsection{Interdisciplinarity}

Despite the interdisciplinary mix of faculty within many games and interactive media programs, and the emergence of a number of interdisciplinary games-focused conferences and journals, recent research indicates that scholarship in the field is becoming less unified and increasingly targeted at narrower, discipline-specific venues [14,33,34]. Deterding [14] argues that this shift is a natural result of the legitimization and integration of games research into more traditional disciplines. It is also possible, however, that these growing divides are a result of (or, at the very least, exacerbated by) the expectation that new faculty should adhere to the culture and norms associated with tenure and promotion in their academic units, rather than participating and publishing in less established and familiar interdisciplinary games and media venues.

Scholars in fields ranging from medicine to digital humanities have identified and wrestled with these problems [16,19,2325,41,43]. In a 2014 article in Nature, Gewin [16] discusses the growing emphasis on interdisciplinary and "cross-cutting" research at funding agencies worldwide, as well as at many universities-but also points out the difficulty this type of research presents for scholars:

[I]nterdisciplinary research can have downsides. Perhaps counter-intuitively, interdisciplinary researchers must carve out a speciality, to form a coherent body of work from disparate strands. This can be difficult if the goal is innovation rather than getting work published, and evaluation metrics can be a major pitfall. Publications in high-profile journals are still the main scorecards for tenure and promotion decisions in many countries. [...] The result is a large gap between the growing number of incentives to conduct interdisciplinary research and the level of career advancement it can offer. Even securing a junior interdisciplinary post is fraught with difficulty (see Nature 476, 115-117; 2011), and career advancement for nontraditional research output poses even more challenges.

Similarly, Rhoten and Parker's 2004 study of five interdisciplinary research centers found that despite their recognition of its intellectual value, early-career tenure-track scientists were deterred from participating in interdisciplinary research due to the professional risks it entailed [43].

One particularly vexing problem for interdisciplinary researchers is the selection of an appropriate venue for the publication of their work. In the context of games research, for instance, a paper assessing the impact of a video game on physical health could be submitted to either a computing conference or a medical journal. Similarly, a project in which game scholars examine the role of mobile augmented reality games in teaching the public about situated history and culture could as easily be published in a games venue as in a history journal.

If a publication venue, regardless of its disciplinary focus, is one with wide dissemination and high impact within a scholarly community, it seems reasonable to think that the choice would not impact a faculty member's promotion and tenure review. However, a committee's lack of familiarity with the expected methods and presentation of research, and/or the reputation and value of publications in an unfamiliar domain, can still result in significant problems for a candidate who publishes their work in a venue outside their college's discipline(s).

There are a growing number of conferences and journals focused on interdisciplinary research in games and interactive, as well as in the digital humanities. Publishing in these venues, however, results in problems that are comparable to cross-disciplinary problems discussed above. In addition, early career scholars are often reluctant to submit their work to these new venues, which have not yet had time to establish their impact in the research literature.

\subsection{Assessing the Quality of Creative Digital Works}

Evaluation for tenure and promotion focuses on assessing the quality of the candidate's scholarly work, and a key factor in that evaluation is demonstrated peer review of the work. For written works, which are the standard method of scholarly dissemination in the sciences and humanities, this peer review typically occurs via conference, journal, or academic press editorial review. Committees generally place significant weight on journal and conference rankings within a discipline, as well as citation rankings for both individual publications and the candidate's overall body of work.

In the arts, however, scholarship includes a wider range of creative output, with guidelines and criteria for evaluation that differ substantially from those used for written works. Creative works in the visual arts can be peer reviewed through juried exhibitions or curated collections, and the works can often be preserved in their original form for evaluation by promotion and tenure committees. Works by performing arts faculty, in contrast, are often ephemeral events, and even if they are preserved through recordings, it is not possible for review committees to fully experience the original production. These works are more likely to demonstrate peer review and impact through published reviews and attendance numbers.

Faculty who are housed in a college with an emphasis on written scholarship, but whose scholarship includes visual or performative work, face a particular challenge when making a case for the scholarly value of that work to their review committees. The College Art Association has produced a set of guidelines that directly address the difficulties that can arise when digital scholarship is reviewed by faculty who are accustomed to using quantitative measures of quality, such as rankings of journals or citations:

It should be noted that the majority of dissemination opportunities in art and design are within venues wherein impact is determined by numerous, varied, and nuanced considerations. Accordingly, venues are not ranked in a 
manner consistent with or parallel to scholarly publications in certain academic disciplines where widely accepted and distinctly ranked orders of importance and impact might exist. (As an example, there is no accepted preeminent art/design award or gallery in the United States.) However, the candidate's documentation of quality and impact measures must then be accepted as valid by the committee members, which may not always be the case. [11]

The growth of programs in the digital humanities, in particular, has pushed universities and disciplines to develop tenure and promotion guidelines that explicitly address the evaluation of digital scholarship $[3,9,12,35]$. While some of these documents are very discipline specific, others are broad enough in their scope to be applicable to scholarship in games and interactive media, as well. As an example, the University of Nebraska has developed criteria for assessing digital research in the humanities that include a significantly broader set of potential criteria, including the impact as evidenced through citations in other scholars' works, the number of unique users viewing the work, and links to the work from other reputable sites [9]. This use of nontraditional but still quantifiable measures is highly applicable to work in games and interactive media.

Another notable component of many digital humanities guidelines is the suggestion that committees include members with experience and knowledge regarding digital scholarship. The American Historical Society, for instance, recommends that committees unfamiliar with digital scholarship solicit input from colleagues with the experience and expertise to evaluate the strengths and weaknesses of the works under review [3].

In computing fields, there have also been attempts to address the challenge of evaluating digital works. The Computing Research Association published a document in 1999 entitled Evaluating Computer Scientists and Engineers For Promotion and Tenurewhich, unfortunately, does not appear to have been updated in recent years. While the document provides guidance on the evaluation of digital artifacts, its focus is on software products and data sets, and the assessment of quality is based primarily on peer-reviewed published research describing the creation of the work:

The artifact is a self-describing embodiment of the ideas. Though publications are necessary for the obvious reasons highlighting the contribution, relating the ideas to previous work, presenting measurements and experimental results, etc. - the artifact encapsulates information that cannot be captured on paper. Most artifacts "run," allowing evaluators to acquire dynamic information. Further, most artifacts are so complex that it is impossible to explain all of their characteristics; it is better to observe them. Artifacts, being essential to the research enterprise, are essential to its evaluation, too. [39]

This emphasis on traditional publications continues to inhibit the ability of junior faculty in computing and humanities programs to engage in creative digital scholarship. In some cases, university policies primarily directed at the digital humanities are broad enough to extend to digital media scholarship in other disciplines. There are also a few games and interactive media programs that have developed guidelines specifically for the evaluation of their faculty's creative works. At the Rochester Institute of Technology, for instance, the School of Interactive Games \& Media developed a set of guidelines to supplement those provided by its parent unit, the College of Computing and Information Sciences [40]. While these guidelines lay out a variety of alternative measures for assessing the quality and impact of digital media projects, the burden of determining and explaining those measures falls primarily to the candidate. and faculty from other departments in the college may not be able-or willing-to determine the validity of those measures.

\subsection{Archiving and Accessing Creative Digital Works}

Scholars in games and interactive media are also faced with the problem of how to provide access to their creative works so that others can interact with it, cite it, and in the case of tenure and promotion, evaluate it. Even when evaluators are willing recognize that original creative works themselves may in fact have more formal criticism, wider dissemination, and higher impact than the papers that follow in its wake, they will still need access to the original work in some form in order to fully evaluate its quality.

When games and interactive media are published on physical media, it is somewhat easier to provide this access to review committees, as well as to include them in library collections and databases. Works that are not available in a self-contained tangible form, however, are significantly more difficult to archive and access. Archiving problems can include the ephemerality of works such as live performances or installations, the dependence of online works on servers and network connectivity, and the use of technology that becomes obsolete or inaccessible. It is also quite difficult to include ancillary components such as design documentation or codebases as a part of an archived creative work.

In recent years, a number of libraries and museums-including both the National Museum of Play [49] and the Library of Congress [38]-have begun to build collections of digital games, and to develop and implement methods for preserving access to those games in the face of rapidly changing technical environments [5,32]. These long-term collections are valuable for research purposes, but do not address the need of junior scholars to provide access to their own works for tenure and promotion evaluation.

Many scholars in games and digital media have chosen to archive their works themselves-on their own servers, via code repositories such as GitHub, or through institutional repositories. In cases where the work is ephemeral and cannot be 
preserved in its original form, they may choose to collect images, videos, and/or narratives that can represent the original work. While these self-archiving efforts can be effective in providing short-term access to the work, they require a significant level of technical expertise on the part of faculty as well as access to appropriate infrastructure.

Even when scholars have access to an institutional repository capable of housing complex digital works, the proliferation of separate individual and institutional archives can make it extremely difficult to locate or find specific works, or to identify connections between works and creators.

When a project involves collaborators from different institutions, additional problems emerge. Faculty (understandably) may not trust that a work archived on the server of a colleague from another institution will be consistently available to them-or to the committee evaluating them. This can lead to multiple copies of the work being archived in different locations, making it difficult to determine which copy should be referenced used when citing the work. The metadata structure for items in institutional repositories may also make it difficult to properly attribute the range of roles associated with a creative work.

\subsection{Citing Games \& Media}

Across academia, and particularly in the sciences, the impact and quality of a work, as well as the reputation of individual scholars, is typically measured through bibliometric analysis

In addition to citation count and impact analysis, review committees also attempt to determine the centrality of a given author's role in collaborative research-often relying on the order of authorship as part of that assessment. However, citation conventions can vary significantly across disciplines. In some fields, for instance, the senior author is listed first. In others, the author who has put the most time into the work is listed first, and the senior faculty member is listed last. In others, authors are listed alphabetically. Researchers found that authors whose names are listed neither first nor last are typically perceived as less important in the research. When research is conducted by interdisciplinary teams, deciding the order of authorship can be as fraught a decision as the choice of venues.

In the case of creative works, where there are seldom traditional "authors," but rather collaborators working in parallel on separate aspects of a project (e.g. design, development, narrative, graphics, production, etc), the order of authorship problem is exacerbated by the fact that there is no agreed-upon standard for identifying roles.

The lack of both citation standards and persistent archiving methods for creative digital work has made it extremely difficult for researchers to properly and consistently cite those works. That, in turn, significantly reduces the evidence of reputation and impact for a given a project, since it is nearly impossible to aggregate citation count across multiple self-archived instances of a work, each using different descriptive metadata .

\section{Potential Solutions to Evaluation Problems}

\subsection{Post-Publication Peer Review}

Academia's near-exclusive reliance upon peer reviewed publications in the evaluation of faculty scholarship has been repeatedly criticized by established researchers. Cole et al's 1981 article "Chance and consensus in peer review" [10] independently evaluated 150 proposal submitted to the National Science Foundation (NSF), and performed an analysis comparing their independent reviews to the actual funding outcomes. They found that "the fate of a particular grant application is roughly half determined by the characteristics of the proposal and principal investigator, and about half by apparently random elements which might be characterized as 'luck of the reviewer draw." Richard Smith, former editor of the prestigious medical journal BMJ, penned a scathing critique of peer review in 2010, opening with this paragraph:

'If peer review was a drug it would never be allowed onto the market,' says Drummond Rennie, deputy editor of the Journal Of the American Medical Association and intellectual father of the international congresses of peer review that have been held every four years since 1989. Peer review would not get onto the market because we have no convincing evidence of its benefits but a lot of evidence of its flaws. [46]

Even the most outspoken critics of pre-publication peer review have had to acknowledge that the practice is so deeply ingrained into academic culture that it is unlikely to be displaced soon. Nonetheless, dissatisfaction with traditional peer review has resulted in the development of new ways of assessing the value of scholarly work. Rather than replacing pre-publication peer review, these approaches can take place after a work has been published, and can provide tenure and promotion committees with additional information on the impact and dissemination of a candidate's scholarly work.

One of the more widely discussed and implemented approaches is that of post-publication peer review (PPPR), in which some form of quantifiable review is performed on articles after their publication. Some proponents of PPPR argue that participation in post-publication review should be open to any reader of the work, while others suggest a second layer of expert peer review.

Altmetrics, which fall into the first category, are one of the more widely-recognized forms of PPPR. This approach gathers and reports references to published scholarly works that come from sources other than other scholarly publications-including mainstream news stories, social media, Wikipedia, and cloudbased references managers such as Mendeley [2]. The result is a quantitative measure that shows a broader range of dissemination and impact, and that is relatively easy for review committees to interpret. However, because this measure does not focus on evaluation by experts within a given discipline, committees may not consider it a reliable measure of quality. 
A less well-known approach to PPPR, which does incorporate expert review, is the use of overlay journals [6-8,36], which have also been referred to as deconstructed journals" [45]. These are journals that resemble anthologies, with expert editorial boards selecting already-published articles for inclusion. The majority of existing overlay journals draw their content exclusively from ArXiv and/or open access journals, which allows them to republish the articles in their entirety without concerns over copyright. It is also possible, however, to create overlay journals that are essentially a peer-reviewed annotated bibliography, with links to the original articles.

In the context of interdisciplinary fields such as games and interactive media, an overlay journal has the potential to address the conflict between the need for pre-tenure faculty to publish their work in journals and conferences familiar to their review committee, and the value of contributing to an interdisciplinary publication. The overlay journal would provide additional evidence of the perceived quality of a given publication, as well as providing it with broader dissemination outside of the faculty member's "home" discipline.

It is not only junior scholars who would benefit from an interdisciplinary overlay journal; such a publication would also provide a valuable resource for all scholars by offering a "best of field" work in games scholarship. Senior faculty in any discipline typically become increasingly specialized in their work, developing deep knowledge in a specific subfield of games and interactive media. Like their departments and colleges, however, as they become more specialized in their focus, they can also become less familiar with important new research in other subspecialties. An overlay journal could offer all researchers a way to stay up to date on relevant research across a wide range of specialties.

The devil, however, is in the details when it comes to introducing a new type of publication in a scholarly context.

On the technical side, it is not clear whether existing overlay journal tools could easily be used for such a project, or if they are too tightly coupled to open source publications. Because this type of overlay journal would point to resources rather than housing them, the technology requirements would focus less on the publication and archiving of the works, and more on the way those works are organized and described.

From a publishing standpoint, there are additional questions. Who would oversee the publication and select the editorial board? A commercial publisher? A professional organization such as HEVGA, DiGRA, or ACM? A university press? An independent cooperative of researchers? Would citations to articles point to the overlay journal, or to the original journal of publication? Would the publication itself be indexed for inclusion in databases like the ACM Digital Library and Google Scholar?
These are hardly impossible questions to answer, but they will require collective interest in and commitment to exploring and answering them.

\subsection{Repositories of Creative Work}

While overlay journals have primarily been used to collect and disseminate written research, they could also serve that purpose for creative digital works. Inclusion of a creative work in conferences or journals, however, does not fully address the archiving problems discussed in section 2.3. Without a permanent resource identifier that can be used for citing a digital work, it is difficult to track impact and dissemination-and citations would fail to include much of the accompanying documentation that would be of value to other scholars. One possible approach to dealing with these archiving issues would be to create digital repositories that have been optimized for games and interactive media.

Unfortunately, academic researchers have consistently resisted the use of institutional digital repositories, despite repeated attempts by academic libraries to encourage and even mandate their use $[13,42,44]$. In many cases, that resistance is due to the fact that it is the institution, not the individual researcher, that benefits from placing items in the repository. In the case of creative digital works, however, the repository would be addressing an acute need, increasing the likelihood of adoption.

For that to happen, however, repositories will need to be better optimized for describing and storing collaborative creative works. Creating repositories for this purpose will require a number of key components:

1) Metadata (schemas and controlled vocabularies) to represent the unique characteristics of games as well as their associated development materials. Significant work in this area has already been done by members of the GAMECIP project $[18,20-22]$, and by Jin-Ha Lee at the University of Washington [27-30]. However, their excellent foundational work has yet to be implemented in university contexts.

2) Repository software capable of housing the range of components associated with a game-such software, development documents, media assets, related papers and presentations. Tools such as a Fedora (and associated frontends for it, such Islandora and Samvera) hold promise in this area $[4,26,48]$.

3) Interface design focused on the needs of both game creators and game researchers. While there is literature focused on interface design for digital repositories in general [17,31,37], the lack of existing game repositories means that work has not yet been applied in that context.

Another factor impacting faculty willingness to use institutional repositories is the fact that these repositories are typically not linked together in a way that facilitates cross-institutional 
(sometimes referred to as "federated") search-a problem that is exacerbated by the poor user interfaces that characterize most repository systems. While repositories can still be effective alternatives to self-archiving by individual faculty, they fail to provide a path for easy discovery of content, which makes them less appealing to scholars than successful large-scale shared repositories like ArXiv and SSRI. To create an effective network of repositories, however, it will first be necessary to design and test individual collections.

\section{Conclusions}

The problems related to evaluation of scholarly work in games and interactive media are significant, but they are not insurmountable. Solutions, however, will require scholars, institutions, and organizations to look beyond traditional journal and conference publishing, and to commit to the development of novel methods for disseminating work in our field.

\section{REFERENCES}

[1] Abertay University. 2017. 20 years of Games. Abertay University School of Design \& Informatics. Retrieved April 29, 2019 from https://www.abertay.ac.uk/schools/schoolof-design-and-informatics/20-years-of-games/

[2] Altmetric. 2015. What are altmetrics? Altmetric. Retrieved June 24, 2019 from https://www.altmetric.com/aboutaltmetrics/what-are-altmetrics/

[3] American Historical Association. 2015. Guidelines for the Professional Evaluation of Digital Scholarship by Historians. Retrieved May 1, 2019 from https://www.historians.org/teaching-and-learning/digitalhistory-resources/evaluation-of-digital-scholarship-inhistory/guidelines-for-the-professional-evaluation-ofdigital-scholarship-by-historians

[4] Christopher Awre and Richard Green. 2017. From Hydra to Samvera: an open source community journey. Insights 30, 3: 82-88. https://doi.org/10.1629/uksg.383

[5] Joanna Barwick, James Dearnley, and Adrienne Muir. 2011. Playing Games With Cultural Heritage: A Comparative Case Study Analysis of the Current Status of Digital Game Preservation. Games and Culture 6, 4: 373390. https://doi.org/10.1177/1555412010391092

[6] Christine Berthaud, Laurent Capelli, Jens Gustedt, Claude Kirchner, Kevin Loiseau, Agnès Magron, Maud Medves, Alain Monteil, Gaëlle Rivrieux, and Laurent Romary. 2014. EPISCIENCES - An overlay publication platform. Information Services \& Use 34, 3-4: 269-277. https://doi.org/10.3233/ISU-140749

[7] J. Brown. 2010. An introduction to overlay journals. Repositories Support Project, UK. Retrieved October 5, 2013 from http://www.rsp.ac.uk/pubs/

[8] J. A. Brown. 2010. Overlay journals, repositories and the evolution of scholarly communication. Presented at: $O R$ 2010: The 5th International Conference on Open Repositories, Madrid, Spain. (2010). Retrieved October 20, 2013 from http://or2010.fecyt.es/Publico/Posters/index.aspx
[9] Center for Digital Research in the Humanities. Promotion \& Tenure Criteria for Assessing Digital Research in the Humanities. The University of Nebraska - Lincoln. Retrieved May 1, 2019 from https://cdrh.unl.edu/articles/promotion

[10] S. Cole, Jr, and G. A. Simon. 1981. Chance and consensus in peer review. Science 214, 4523: 881-886. https://doi.org/10.1126/science.7302566

[11] College Art Association of America. 2016. Guidelines for Retention and Tenure of Art and Design Faculty. CAA. Retrieved May 1, 2019 from https://www.collegeart.org/standards-andguidelines/guidelines/art-and-design-tenure

[12] College Art Association and Society of Architectural Historians. 2016. Guidelines for the Evaluation of Digital Scholarship in Art and Architectural History. Retrieved May 1, 2019 from https://www.collegeart.org/pdf/evaluating-digitalscholarship-in-art-and-architectural-history.pdf

[13] Philip M. Davis and Matthew J. L. Connolly. 2007. Institutional Repositories: Evaluating the Reasons for Non-use of Cornell University's Installation of DSpace. DLib Magazine 13. Retrieved November 29, 2010 from http://www.dlib.org/dlib/march07/davis/03davis.html

[14] Sebastian Deterding. 2017. The Pyrrhic Victory of Game Studies: Assessing the Past, Present, and Future of Interdisciplinary Game Research. Games and Culture 12, 6: 521-543. https://doi.org/10.1177/1555412016665067

[15] Entertainment Software Association. College Video Game Programs. The Entertainment Software Association. Retrieved April 28, 2019 from

http://www.theesa.com/about-esa/courses-certificatesdegree-programs/

[16] Virginia Gewin. 2014. Interdisciplinary research: Break out. Nature 511, 7509: 371-373.

https://doi.org/10.1038/nj7509-371a

[17] Laura Icela González-Pérez, María-Soledad RamírezMontoya, and Francisco J. García-Peñalvo. 2018. User Experience in Institutional Repositories: A Systematic Literature Review. International fournal of Human Capital and Information Technology Professionals 9, 1: 70-86. https://doi.org/10.4018/IJHCITP.2018010105

[18] Greta de Groat, Eric Kaltman, Marcia Barrett, Christine Caldwell, Glynn Edwards, Henry Lowood, and Noah Wardrip-Fruin. 2015. Core Metadata Schema for Cataloging Video Games Version 1. University of California Santa Cruz, Santa Cruz, CA. Retrieved from https://gamecip.soe.ucsc.edu/publications

[19] Katri Huutoniemi. 2012. Evaluating Interdisciplinary Research. In The Oxford Handbook of Interdisciplinarity (Reprint), Robert Frodeman, Julie Thompson Klein and Carl Mitcham (eds.). Oxford University Press, 309-320. Retrieved April 7, 2019 from https://scholar.google.com/scholar_lookup?hl=en\&publica tion_year $=2010 \&$ pages $=309$ -

320\&author $=$ K. + Huutoniemi\&title $=$ Evaluating + interdiscip linary+research

[20] Eric Kaltman. 2017. The Stabilization, Exploration, and Expression of Computer Game History. UC Santa Cruz, Santa Cruz, CA. Retrieved May 10, 2019 from https://escholarship.org/uc/item/4rn402db 
[21] Eric Kaltman, Noah Wardrip-Fruin, Henry Lowood, and Christy Caldwell. 2015. Methods and Recommendations for Archival Records of Game Development: The Case of Academic Games. In Proceedings of the 10th International Conference on the Foundations of Digital Games. Retrieved May 21, 2019 from

http://www.fdg2015.org/papers/fdg2015_paper_45.pdf

[22] Eric Kaltman, Noah Wardrip-fruin, Mitch Mastroni, Henry Lowood, Greta de Groat, Glynn Edwards, Marcia Barrett, and Christy Caldwell. 2016. Implementing Controlled Vocabularies for Computer Game Platforms and Media Formats in SKOS. Journal of Library Metadata 16, 1: 1-22. https://doi.org/10.1080/19386389.2016.1167494

[23] Julie T. Klein. 2008. Evaluation of interdisciplinary and transdisciplinary research: a literature review. American journal of preventive medicine 35, 2: S116-S123.

[24] Julie T. Klein. 2015. Interdisciplining Digital Humanities: Boundary Work in an Emerging Field. University of Michigan Press.

[25] Julie Thompson Klein. 1990. Interdisciplinarity: History, theory, and practice. Wayne state university press.

[26] Carl Lagoze, Sandy Payette, Edwin Shin, and Chris Wilper. 2006. Fedora: an architecture for complex objects and their relationships. International fournal on Digital Libraries 6, 2: 124-138. https://doi.org/10.1007/s00799-0050130-3

[27] Jin Ha Lee, Rachel Ivy Clarke, and Andrew Perti. 2015. Empirical evaluation of metadata for video games and interactive media. Fournal of the Association for Information Science and Technology 66, 12: 2609-2625.

[28] Jin Ha Lee, Rachel Ivy Clarke, and Stephanie Rossi. 2016. A qualitative investigation of users' discovery, access, and organization of video games as information objects. Journal of Information Science 42, 6: 833-850. https://doi.org/10.1177/0165551515618594

[29] Jin Ha Lee, Natascha Karlova, Rachel Ivy Clarke, Katherine Thornton, and Andrew Perti. 2014. Facet analysis of video game genres. iConference 2014 Proceedings.

[30] Jin Ha Lee, Joseph T. Tennis, Rachel Ivy Clarke, and Michael Carpenter. 2013. Developing a video game metadata schema for the Seattle Interactive Media Museum. International fournal on Digital Libraries 13, 2: 105-117. https://doi.org/10.1007/s00799-013-0103-x

[31] Edward Luca and Bhuva Narayan. 2016. Redesigning the Open-Access Institutional Repository: A User Experience Approach. In Digital Libraries: Knowledge, Information, and Data in an Open Access Society (Lecture Notes in Computer Science), 275-281.

[32] Jerome P. McDonough, Robert Olendorf, Matthew Kirschenbaum, Kari Kraus, Doug Reside, Rachel Donahue, Andrew Phelps, Christopher Egert, Henry Lowood, and Susan Rojo. 2010. Preserving Virtual Worlds Final Report. Retrieved May 1, 2019 from https://www.ideals.illinois.edu/handle/2142/17097

[33] Edward F. Melcer, Truong-Huy D. Nguyen, Zhengxing Chen, Alessandro Canossa, Magy Seif El-Nasr, and Katherine Isbister. 2015. Games Research Today: Analyzing the Academic Landscape 2000-2014. In FDG.
[34] Edward Melcer and Katherine Isbister. 2017. Toward Understanding Disciplinary Divides Within Games Research. In Proceedings of the 12th International Conference on the Foundations of Digital Games (FDG '17), 48:1-48:4. https://doi.org/10.1145/3102071.3106355

[35] Modern Languages Association. 2012. Guidelines for Evaluating Work in Digital Humanities and Digital... Modern Language Association. Retrieved April 30, 2019 from https://www.mla.org/AboutUs/Governance/Committees/CommitteeListings/Professional-Issues/Committee-on-InformationTechnology/Guidelines-for-Evaluating-Work-in-DigitalHumanities-and-Digital-Media

[36] M. Moyle and A. Lewis. 2008. RIOfA (Repository Interface to Overlaid fournal Archives) project: final report. UCL (University College London), London, UK. Retrieved October 20, 2013 from http://discovery.ucl.ac.uk/12562/

[37] Bhuva Narayan and Edward Luca. 2017. Issues and challenges in researchers' adoption of open access and institutional repositories: a contextual study of a university repository. Information Research 22, 4.

[38] Trevor Owens. 2012. Yes, The Library of Congress Has Video Games: An Interview with David Gibson. The Signal. Retrieved April 30, 2019 from //blogs.loc.gov/thesignal/2012/09/yes-the-library-ofcongress-has-video-games-an-interview-with-davidgibson/

[39] David Patterson, Lawrence Snyder, and Jeffrey Ullman. 1999. Evaluating Computer Scientists and Engineers For Promotion and Tenure. Retrieved May 1, 2019 from https://cra.org/resources/best-practice-memos/evaluatingcomputer-scientists-and-engineers-for-promotion-andtenure/

[40] Andrew Phelps. 2012. Metrics \& Processes for Promotion and Tenure in Interactive Games \& Media: A Whitepaper. Retrieved April 28, 2019 from

https://andyworld.io/writing/documents/IGM_promotion _and_tenure_whitepaper.pdf

[41] Martha E. Pollack and Marc Snir. 2008. Promotion and Tenure of Interdisciplinary Faculty. Retrieved April 29, 2019 from https://cra.org/resources/best-practicememos/promotion-and-tenure-of-interdisciplinaryfaculty/

[42] Richard Poynder. 2016. Q\&A with CNI's Clifford Lynch: Time to re-think the institutional repository. The Open Access Interviews.

[43] Diana Rhoten and Andrew Parker. 2004. Risks and Rewards of an Interdisciplinary Research Path. Science 306, 5704: 2046-2046.

https://doi.org/10.1126/science. 1103628

[44] Dorothea Salo. 2008. Innkeeper at the Roach Motel. Library Trends 57, 2: 98-123. https://doi.org/10.1353/lib.0.0031

[45] John W. T. Smith. 1999. The deconstructed journal - a new model for academic publishing. Learned Publishing 12, 2: 79-91. https://doi.org/10.1087/09531519950145896

[46] Richard Smith. 2010. Classical peer review: an empty gun. Breast Cancer Research 12, 4: S13. https://doi.org/10.1186/bcr2742 
[47] The Princeton Review. 2019. Top 25 Graduate Schools for Game Design. The Princeton Review. Retrieved April 24, 2019 from https://www.princetonreview.com/collegerankings/game-design/top-25-game-design-grad

[48] David Wilcox and Evviva Weinraub. 2017. Supporting Digital Preservation and Access with Fedora. Retrieved May 21, 2019 from http://library.ifla.org/1758/

[49] 2014. International Center for the History of Electronic Games. The Strong: National Museum of Play. Retrieved April 30, 2019 from

https://www.museumofplay.org/about/icheg 